ConNotas. Revista de Crítica y teoría literarias / Vol. VI, Núm. 10 / 2008

\title{
Configuración de personajes en contrapunto en Duelo de noche, de María Antonieta Mendívil
}

\author{
CÉSAR Avilés ICEDo*
}

Resumen:

El análisis se centra en el contrapunteo que hace progresar la narración, y trata de evidenciar las preocupaciones éticas y estéticas de su autora: la configuración de dos héroes (madre e hija) marcados por dos posturas ideológicas correspondientes a sendos contextos donde estos personajes se desenvuelven. La madre se configura en una lucha con su entorno, mientras que la hija acusa una preocupación más "moderna": la definición de sí misma a través de la exposición de sus conflictos internos. En ambos casos prima, sin embargo, un elemento común: la incapacidad de comunicarse con los otros, una suerte de alienación que las margina como mujeres y como individuos. Mediante el presente análisis se descubrirán las funciones significativas de algunos de los elementos espacio- temporales que provocan la definición de estos personajes y sus circunstancias, y con ello se intentará, además, ubicar la novela en el proceso de la literatura del norte de México.

Palabras clave:

Configuración de personajes, contrapunto, identidad, alienación, literatura del norte de México.

* Universidad de Sonora. 


\section{Duelo de noche y los antecedentes de la narrativa regional norteña.}

En la literatura producida y consumida en el Noroeste de México, hasta antes de la década de los ochentas del siglo XX, era excepcional que algún escritor se aventurara en la exploración de procedimientos estilísticos, temáticos y composicionales como lo hacían sus colegas de las grandes metrópolis del país y de otros países. Era notable el descuido en el delineamiento de los personajes, o al menos este aspecto recibía poca atención; así, tales personajes parecían una proyección de las preocupaciones del autor, que entendía la literatura -según se puede colegir- como un medio para educar, adoctrinar o vehicular de forma abierta un mensaje entendido como éticamente positivo. La máxima aspiración era -en el mejor de los casos- retratar supuestas realidades en conflicto o testimoniar sucesos relevantes de la historia regional. La voz autoral sofocaba las voces de los personajes produciendo textos que se emparentaban más con la literatura decimonónica, muy ajena a la que se producía en las urbes cosmopolitas que le eran contemporáneas. De esta suerte, los personajes parecían figuras esquemáticas sin una lógica interna, o criaturas conducidas a un fin predeterminado cuyo destino entonces era muy previsible para los receptores.

Los vientos de cambio llegan con narradores y dramaturgos que despuntan durante las tres últimas décadas del siglo XX, con una producción que avanza sobre las mismas vías "modernas" que primaban en otras latitudes del orbe. ${ }^{1}$ En poesía y ensayo el panorama era más alentador pues ya existían poetas y ensayistas con una visión más universalista.

En el inicio de este siglo la profesionalización del ejercicio escritural ha propiciado la emergencia de narradores que ensayan

${ }^{1}$ Aquí me estoy refiriendo a autores que producen su literatura y su teatro en esta región del país, no a los que se marcharon y produjeron sus obras desde los centros urbanos cosmopolitas, desde donde se irradiaba otro tipo de cultura y se utilizaban otros medios para su producción y consumo. 
procedimientos artísticos más acordes con los de sus colegas de las metrópolis. Incluso, los medios de publicación y difusión han entrado en sistemas globalizados pues ahora se publica en editoriales del centro del país e incluso de otros países.

En este contexto, Duelo de noche, la segunda novela de María Antonieta Mendívil, si bien no abre un sendero nuevo, sí transita por uno pocas veces explorado por las narrativas regionales norteñas y pretende brindar dos personajes integrales en su configuración. Esto se traduce en una caracterización de personajes con conciencia propia, con relieve psicológico y con una relación lógica entre los estímulos del entorno y las reacciones con las que ellos responden. Así, se presentan los relieves de personalidades complejas, no caricaturas o máscaras a través de las cuales se escucharía la voz de su autora.

\section{Los personajes}

La novela toma como personajes a Concha y Sara, una madre y su hija, que durante la noche de agonía de la primera recuerdan sus vidas y reflexionan sobre los acontecimientos que las marcaron. Mediante este choque de monólogos se ponen de manifiesto algunos elementos que me interesa resaltar aquí: en primer lugar el contrapunteo entre los personajes, lo cual deviene en el delineamiento de uno y otro; y, en segundo, y concatenado con lo anterior, se configura un espacio-tiempo que intenta representar la realidad contextual histórica donde estos personajes se debaten afirmando o diluyendo su identidad individual. En este contrapunteo se establecen más contrastes que diferencias. En Concha la lucha vital se da en la búsqueda de condiciones concretas de superviviencia. Dentro de lo que cabe, su vida interior está más o menos resuelta, de ahí que la atención se centre en un entorno sumamente complejo que contradice la idea romantizada de que los espacios rurales son puros e incorruptos. Concha se desenvuelve en un entorno donde los problemas se multiplican: una familia disfuncional con una madre que abandona al esposo con sus hijas y sólo regresa para provo- 
car más problemas, o para hacer más difícil la convivencia entre ellas, que vivían en cierta armonía durante su ausencia; una situación económica marcada por la precariedad, especialmente durante su época de soltería y los primeros años de su propio matrimonio; unas relaciones de noviazgo tensionadas por las marcas de género; una división entre las familias de sus padres, condicionadas por sus predeterminaciones sociales, lo que provocará choques de prejuicios y repercutirá en la infelicidad de casi todos los integrantes de esas familias. Al final de tantos avatares podemos decir -en términos del registro léxico propio de la novela- que Concha habrá alcanzado una economía mejor y cierta paz con el marido, pero no la plenitud anhelada de forma confesa: la que le daría una relación armoniosa con los hijos y la tranquilidad espiritual que la reconcilie con los fantasmas del pasado.

La vida de la hija está mucho mejor resuelta en el aspecto económico, así que en su caso la atención del relato se centra en una lucha interior, en un proceso donde el fin último es la construcción de la identidad, de la recuperación del sentido que tiene la relación con los otros, de la ubicación de una religiosidad donde Dios es omnipresencia como preocupación pero silencio ante las preguntas existenciales que ella se plantea y ausencia ante las demandas inmediatas de auxilio.

Así, la parte de la madre es rica en anécdotas, en los vaivenes de la fortuna que al final logra estabilizarse cuando el marido se consolida como agricultor relativamente exitoso, en episodios que dan cuenta de épocas y de espacios sociales exteriores, donde incluso se puede establecer una datación del momento histórico que enmarca los acontecimientos, sea por la música que se baila o se canta, sea por las costumbres de cortejo amoroso o de cualquier signo marcado por la moda aludida. Aunque en el caso de Sara, también hay datos que permiten la ubicación histórica, este aspecto se minimiza ante un cuestionamiento mucho más intimista.

La construcción de estos personajes depende, pues, de la alteridad que se establece entre ellos, marcada en dos niveles en el texto: en el de las ideas, mediante un contraste permanente; y en el de la composición -entendida como la organización de las partes con el 
todo- ligando alternativamente el relato de ambas historias vitales: el fin de un episodio de una vida, sirve para engarzar el inicio del episodio de la otra. Por otro lado, es destacable esa articulación de los dos monólogos, pues desde ahí se significa la incapacidad de diálogo entre madre e hija, negadas por múltiples razones para establecer un punto de encuentro entre ellas.

Como es previsible, las principales diferencias entres estos personajes se deben a posturas generacionales, manifiestas en modalidades variadas. Así, muy al principio del texto, en la exposición discursiva inmediata, se deja clara la naturaleza distinta entre estos dos personajes en cuanto a la disposición vital con que enfrentan la realidad. En ese inicio, declara Sara: "Tal vez ésa fue la primera diferencia que tuvimos mi madre y yo. A mí no me bastaba esa frase [“Quién sabe por qué, pero así es”]. Para mí era la pared levantada abruptamente ante mi curiosidad. Yo sí quería saber por qué" (14). Esa "curiosidad" remite por supuesto a una actitud activa ante los estímulos que la realidad impone. Ello se traduce a todos los ámbitos: en el modo en que ambas asumen el papel que ocupan como hijas y como hermanas, en la relación de pareja con sus respectivos novios, en el rol de sumisión con que Concha acepta ser dependiente del marido, en oposición a la rebeldía de Sara (que se rehúsa a casarse y a abrazar la maternidad como misión prioritaria de la mujer). Es claro que estos personajes representan a dos mujeres de sus respectivos contextos: Concha revela un perfil casi estático en un universo social conservador, pese a que su propia madre no se parece en nada a la típica madre abnegada que predomina en las representaciones culturales de los años en los que supuestamente ocurre su historia (décadas de los 50 y 60); Sara, se define en continuidad y ruptura con el universo que se articula en torno a Concha. Por ello la novela casi es un documento de antropología social porque testimonia dos maneras casi arquetípicas de representarse en el mundo. 


\section{Un recorte desde los constructos socio-culturales}

La narración hace uso de los referentes que pueden perfilar los imaginarios que determinan las aspiraciones vitales de estos seres. Los principales elementos que se utilizan para este fin son un recorte figurativo de la realidad socioeconómica marcada por el racismo, la manera como se concibe la relación de pareja y la construcción ideológica de la divinidad.

Uno de los elementos movilizados para introducir las preocupaciones esenciales del libro son las referencias al cine. Para Concha las artistas que ve en la pantalla son el modelo para sí, y para evadir su propia realidad: "Siempre me gustó cantar. Y era muy fantasiosa. Me iba al monte, me sentaba en una piedra e imaginaba ser una artista de cine o una de las que cantaban en las carpas que iban a la ciudad. Me ponia en pose, cantaba y gesticulaba como las artistas" (31). ${ }^{2}$

También la fantasía contribuye a acrecentar el imaginario que nutre a Sara para conformar (para con-formar) a la madre y su relación con ella: "Me encantaba verte en las fiestas. Siempre has sido tan elegante, tan bella; imaginaba que eras una artista de verdad y que yo era tu hija. Imaginaba que un día iba a cantar contigo y que todos nos aplaudirían. Y que nos presentarían como "las hijas del trueno" (31). Es notorio cómo la narración propone un personaje proyectándose en otro, encontrándose en el otro en la casi fusión que, al menos en una etapa de la vida, se tiene con él. Y cuando Sara todavía no se escinde de esa figura maternal, busca sus propias ensoñaciones de nuevo en los imaginarios que representa el cine:

Durante la hora de recreo, caminaba por el salón, maleta en mano. Yo era una muchacha viajera, rubia, que iba de tren en tren, con una maleta cargada de piedras brillantes y vestidos largos y elegantes. Durante la hora del recreo, atravesaba una y otra vez el salón, atravesaba el mundo. (45)

${ }^{2} \mathrm{Al}$ citar las palabras de Concha, respetaré el uso de cursivas con que el texto contrasta las de Sara. 
Si en Concha la recepción que ella tiene del cine cataliza sus ensoñaciones, y con ello alcanza un sucedáneo de satisfactores "espirituales" ante una realidad que no le es propicia, en Sara la recepción de las películas revela un elemento ideológicamente muy cargado: la cabellera rubia, los ojos azules, los ropajes elegantes, los accesorios de piedras preciosas y esa actitud de exótica viajera (proyectado desde ese ir y venir por el salón con la maleta), están marcando un imaginario que sitúa al personaje en un universo ajeno al de la realidad mexicana y lo que por lo general el cine nacional retrataba; corresponden más bien a la figuración que producía y reproduce el cine extranjero, preponderantemente el estadounidense. Como veremos más adelante, en el imaginario social de Concha también pesa ese elemento racial, pero a ella esa carga le viene de otras fuentes de menos fácil identificación y de orígenes más acendrados en la tradición de Occidente.

La referencia cinematográfica opera también en sentido contrario al de la evasión fantasiosa de las circunstancias que envuelven al personaje cuando se quiere remarcar lo lejana que es esa realidad ficticia. Concha, al verse descubierta en sus representaciones de gran cantante, se siente aniquilada por la visión del otro; ese otro no sólo la devuelve a su realidad miserable, sino que hace que esa visión que tiene de sí misma se vuelva todavía más miserable:

Una vez descubri que un muchacho me escuchaba, justo detrás de mí. Eh, se cree artista, se burló. Mi mano estaba levantada al cielo, me callé al momento, bajé la mano y sali corriendo, llorando. Pocas veces he pasado vergüenza mayor. No hay nada peor a que alguien te devuelva a la realidad cuando tú estás instalada en la fantasía. (31)

Lo cual connota algo que aparece como un absoluto en la configuración del personaje: la anulación del ser ante el otro que descalifica o que simplemente no valora aquello que es tan altamente preciado en el mundo de valores que ahí rige. Por ello, la novela toda dibuja en la madre un personaje muy susceptible a la descalificación, al poco valor que se otorga a sí misma, a expensas de lo que diga el otro. 
El texto proporciona los elementos para que el lector encuentre una explicación de esta baja autoestima en la genealogía de la familia del personaje, lo cual hace coherente su debilidad: Concha es hija de un español proveniente de una familia muy racista y discriminante y de una mujer humilde y morena que además es hija de una mujer "vulgar" (según la califica la misma narradora) pues es la madre soltera de varios hijos de diferentes padres, que ve en el futuro yerno "la oportunidad de acomodar a su hija, antes de que la embarazara un pobretón del pueblo".

Es de notar la valoración que expresa Concha sobre la unión de sus padres:

Nadie estaba para rechazar a don Rafael Jimeno, menos una bija de mujerzuela, como le decía papá a mamá cuando se enojaba [...] Cuando va llegando tu abuelo con su familia, imaginate. Mi abuela Remedios se quiso morir, por la clase de muchacha que llevaba. Para empezar era morena, para seguir la llevaba en pecado, para terminar no era de la alta sociedad del pueblo y como añadidura, la abuela no tenía muchas ganas de que sus hijos se casaran. (35)

Concha no toma con distancia lo hechos, sino que asume casi la misma actitud y postura racistas y prejuiciosas que tiene su abuela paterna, lo cual la condena a vivir con ese sentimiento de inferioridad que la aleja de los demás y la anula interiormente. En consecuencia en el mundo que evoca Concha de sus primeros años el ambiente familiar es hostil, de desgracia y desavenencia, donde de nuevo para ella lo rescatable en el padre es su nacionalidad y el color de su piel:

Mi mamá siempre odió a mi papá. Lo insultaba diciéndole viejo pelón, bueno para nada, viejo desabrido. Nosotras oíamos eso siempre. Yo iba y me escondia en un baúl, que según papá lo habia traído mi abuelo de España lleno de telas finas; nosotros lo utilizábamos para guardar nuestra ropa rota y sucia que vestíamos siempre. Alli pensaba: pero mi papá es tan guapo. Tiene lo ojos azules y es español. (36) 
La carga ideológica sobre el mestizaje nunca asumido y el refuerzo del racismo de la familia paterna y por el padre mismo, es expresada por la Concha-narradora cuando refiere la visita del padre a la escuela:

Una mañana papá llegó a la escuela- Eso era parte de la nueva vida. Nunca babian ido a vernos y saber cómo estábamos. Me acerqué para que todo mundo se enterara de que ese señor rubio, alto, delgado, de ojos azules, vestido con pantalón oscuro era mi padre. Al verme papá se volvió hacia la maestra y se quejó: mire nada más qué prieta está Concepción. Sólo quiero pedirle que por favor ya no la deje salir al recreo, porque va a acabar mora. La maestra la miró y dijo: ya oíste Concha. En lugar de rebelarme, me sentí avergonzada de que mi padre evidenciara mi color, un color del que mi familia paterna se avergonzaba. (44-45)

En este mismo orden de ideas, hay elementos narrativos que cumplen una función sígnica adicional a la meramente enunciativa que aparece a primera vista. Los piojos, mencionados tanto por Concha como por Sara, funcionan como elementos simbólicos y metafóricos de realidades no designadas directamente, pero funcionan como elementos que aluden a la marginación y el menosprecio. En el caso de Concha, como ella es la que padece los piojos, los bichos tienen un valor directo en la recepción negativa que ella padece de su abuela y sus tías paternas:

Saliamos corriendo a recibirlas [a la abuela y las tías], pero estiraban los brazos para detenernos. A distancia nos abrian los cabellos entre las trenzas para ver nuestros cráneos. Siempre nos descubrian piojos. La abuela hacía una señal con su sombrilla y las tías nos sentaban al sol, deshacian las trenzas, sacaban unos pomos de veneno apestoso, mojaban algodones y los exprimian sobre las llagas que ya teniamos.

Me gustaba ver a mis hermanas cuando les exprimian veneno en las llagas. Claramente se veían los piojos negros desparramarse, expulsados de las llagas. Ya sé que es muy desagradable, pero era un alivio saber que alguien llegaba a limpiarnos y a despiojarnos. (40) 
Los piojos son también signo de miseria y degradación, de un mundo al que se recuerda con desagrado, no tanto por lo que era (la descripción conserva una valoración neutra, a pesar del tema que puede llegar a la escatología): Los piojos me recordaban todo lo feo que tenian nuestras vidas sin desearlo ni buscarlo. Los piojos también llegaban solos sin que nos diéramos cuenta [...] (40). Por esto no es de extrañarse que las reflexiones que se leen inmediatamente a la alusión a los piojos remitan a la condición de desgraciada economía básica y de marginación social literal: Ninguna de nosotras quería vivir en las afueras de la ciudad, en una casita tan miserable, rodeadas de basura y monte. Ninguna de nostras nos sentiamos felices de tener un padre severo y arisco, una madre tan indiferente. No deseábamos tanta pobreza y desamparo (20). Los piojos se asocian pues no sólo a la pobreza y suciedad, sino a la poca armonía familiar y a la miseria espiritual del matrimonio que prohija a Concha y sus hermanas.

A Sara le ocurre a la inversa que a su madre con los piojos: como todas sus amigas padecen esos bichos es a ella a la que la apartan con la intención de que no se contagie. Paradójicamente el resultado es el mismo que con Concha: la marginación del entorno social inmediato. Cuando la maestra separa a la niña de las demás compañeras a instancias de su padre, ella se siente muy avergonzada, separada de su comunidad. A ella le gustaría también tener piojos para ser igual que sus compañeras:

No sé si es posible que alguien se sintiera más avergonzada que yo en ese momento. Me estaban separando de mis amigos, como si a mí me atemorizaran sus piojos. [...] A partir de ese día, no tuve compañeros de recreo. Solo la maestra iba y me buscaba bajo las escaleras o en el árbol sombrío que estaba en el patio. [...] Ella me alejaba de mis amigos, ella me abrumaba con sus atenciones y alabanzas. Yo sólo quería jugar, aunque me pegaran los piojos, aunque me pegaran y humillaran. (45-46)

De una manera similar al valor connotativo que tienen los piojos, están las menciones del baúl que el abuelo había traído de Es- 
paña con telas finísimas y que después se utilizaba como depósito de las ropas sucias y raídas.

\section{La identidad}

Sin duda uno de elementos más importantes en la configuración del personaje de Sara es la búsqueda de su identidad, lo cual moviliza dos aspectos vitales que no tienen conexión aparente: la relación de pareja y la búsqueda de Dios. Esto da ocasión de la exposición que hace la propia Sara de sus luchas internas:

Nadie sabía por qué mi cuerpo se sentía desnudo al exponerme frente los demás. Nadie sabía los pasadizos entre mis cavernas internas. Nadie sabía las voces que se enfrentaron en cruentas batallas en mi mente. Nadie sabía de mi constante y profunda sensación de despojo, que era dolorosa y al mismo tiempo liberadora. Nadie sabía lo que se siente estar huérfana y sin Dios, y caminar por un laberinto de espejos donde sólo se ve uno mismo, y nunca se es uno mismo, sino múltiple. (119-120)

Es esta capacidad de preguntarse todo y de poner en duda las verdades establecidas como la que hace que Sara se desprenda no sólo del personaje de la madre, en cuanto a su configuración como personaje lineal y monolítico, sino de cualquier personaje tramado convencionalmente. Sara representa la aportación de los pocos personajes complejos que ha generado la literatura norteña del país. Complejo porque los valores habituales no son la moneda con la que ella transita por el mundo; por ello, inusitadamente para los demás, Sara rompe su relación con su novio cuando, según lo expresado por el mismo personaje, lo que se espera es que se case de inmediato. La construcción del personaje privilegia por sobre cualquier valor el de la libertad: 
Libertad era vivir en un apequeña casa, y yo elegir cada objeto. Libertad era dibujar y romper lo dibujado, sin el imperativo de enmarcarlo en las paredes. Libertad era caminar por las calles de la ciudad sin tener que avisar a nadie de mis pasos errantes. Libertad era lanzarme a la vida, así, consciente y sin paracaídas. Libertad era yo conducir mi caída. (129)

Por ello también corta las amarras que la atan a la familia, y que, ya hecho esto, se cuestione el dudoso valor que tiene esa libertad recién estrenada, pues ésta ha sido obtenida casi por descuido de la familia, como un robo, a través de una trampa artificiosa.

Muy al contrario, para Concha la felicidad está en la unión amorosa, en la entrega al marido con el que se ha casado con la convicción de que en él encontrará su prolongación vital, en un ideal que en comparación con lo expresado por Sara parece ingenuo; de hecho, la soledad para ella es un castigo, una condena por una acto fallido o doloso.

En el extremo de la negación de los absolutos, Sara llevará su reflexión a un punto donde sólo la paradoja le ofrecerá respuestas:

Estuve quince días en la ermita. Sola. Fue una experiencia muy fuerte [...] Al estar a solas y en silencio, la ausencia radical de Dios fue una fuerza que pareció expulsarme a cada momento y me mantuvo en la línea de la renuncia. [...] Finalmente renuncié. Dios no sería visto por mí como un destino, sino como una ausencia presente, acompañante. (138)

Las interrogantes que tiene Sara la conducen a una vorágine donde quedan pocas certezas de las cuales asirse. La principal preocupación que queda cuando se ha renunciado a casi todo lo terreno, es la idea de Dios:

No es fácil creer en un Dios a secas, que nunca se revela -Dice-. Cada día me pegunto qué es Dios, y si realmente esta ausencia que resuena en mi interior es Él o el vacío de una idea que mi mente ha inventado desde niña para escapar de la asfixia [...] Muchas veces pienso que yo he inventado a Dios, 
que este Dios es mi otro yo, que este Dios es la sombrilla que me cubre de la tormentas y atrasa mi caída. (146)

Y es la presentación de un personaje con tales características lo que dota la novela una acentuada polaridad. Por un lado, en un trazado muy lógico de causa-efecto, está el perfil que se proporciona de Concha; por otro, en las antípodas de un personaje así, está Sara. La novela presenta dos personajes antagónicos en el modo como están concebidos: uno con un pie en la racionalidad cartesiana, con todo y los conflictos que deben enfrentar, el otro con todas las incertidumbres que apuntan a una concepción del mundo mucho más modernizada. Finalmente la lucha de una es con el mundo; mientras que la lucha de la otra es consigo misma.

En estos términos la literatura regional asoma a otros horizontes; sin embargo, me atrevo a señalar que la empresa queda a medio camino, porque el texto pierde su carril en dos aspectos que merman su valía. El primero es la inconsistencia en la perspectiva con que se cuentan los hechos: tanto el personaje de la madre como el de la hija no sostienen la distancia con la que se evoca el pasado. En ocasiones, como cuando Concha relata la primera ocasión que menstrúa, o cuando se narra la ocasión en que ella sorprende a sus padres teniendo relaciones sexuales, la perspectiva es la del personaje en el tiempo del enunciado; sin embargo en la mayor parte de su relato domina la visión de alguien que desde un presente emite juicios de valor sobre su pasado. El segundo es de orden estilístico y consiste en que los dos personajes acusan el mismo registro de habla, lo cual resultaría imposible debido a su muy diferente preparación académica y experiencia vital. Por otro lado, la novela deja un vacío en la exploración de un personaje tan provocador como la madre de Concha, una auténtica outsider que reta todos los convencionalismos y mira la vida desde la periferia; porque sólo desde ahí, la institución familiar es absolutamente vulnerada (hijos de padres diferentes, seducción al novio de la hija, etc.).

En la revisión histórica que se haga de la literatura del noroeste de México, estimo que la novela se valorará porque aporta esta construcción de personajes en contrapunto y porque instala con Sara, 
un personaje de interesantes relieves que apuntan a un héroe moderno, en tanto que su lucha con su entorno está atenuada por el volumen y vigor de las voces que sostienen una ríspida disputa en el interior de su conciencia, porque incluso aquí sí se puede hablar de conciencia.

\section{Bibliografía}

Arfuch, Leonor, comp. Identidades, sujetos y subjetividades. Buenos Aires: Prometeo Libros, 2005.

Mendívil, María Antonieta. Duelo de noche. Madrid: Almuzara, 2007. Pimentel, Luz Aurora. El espacio en la ficción. Ficciones espaciale: la representación del espacio en los textos narrativos. México: Siglo Veintiuno/Universidad Nacional Autónoma de México, 2001. . El relato en perspectiva: estudio de teoría narrativa. México: Siglo Veintiuno/Universidad Nacional Autónoma de México, 1998. 